http://jmscr.igmpublication.org/home/ ISSN (e)-2347-176x ISSN (p) 2455-0450 crossref DOI: https://dx.doi.org/10.18535/jmscr/v7i7.83

\title{
Study of Surgical Outcome after Modified Radical Mastoidectomy
}

\author{
Authors \\ Dr Padam Chand Jain ${ }^{1}$, Dr Richa Gupta ${ }^{2 *}$, Dr Prerna Mandowara ${ }^{3}$, \\ Dr Rajendra Kumar Gorwara ${ }^{4}$ \\ ${ }^{1}$ Professor, Deptt of ENT, Pacific Medical College and Hospital, Udaipur \\ ${ }^{2}$ Associate Professor, Deptt of ENT, Pacific Medical College and Hospital, Udaipur \\ ${ }^{3}$ Assistant Professor Department of ENT, Pacific Medical College and Hospital, Udaipur \\ ${ }^{4}$ Associate Professor, Deptt of Entire, Pacific Medical College and Hospital, Udaipur \\ *Corresponding Author \\ Dr Richa Gupta \\ Associate Professor, Deptt of ENT, Pacific Medical College and Hospital, Udaipur, India
}

\begin{abstract}
CSOM (chronic suppurative otitiis media) is a major public-health problem, Chronic suppurative otitis media (CSOM) is a chronic suppurative inflammation of mucoperiosteal lining of middle ear cleft due to suppurative organisms. It leads to ossicular necrosis of bone. It is one of the common diseases in ENT practice. The surgical outcomes may be assessed in terms of hearing \& healing of middle ear pathology. The present study was done on 64 cases of CSOM. The main aim of study was assessment of improvement of hearing preoperatively and postoperatively and study the extent of damage to ossicles.

Keywords: CSOM. Canal wall down. Hearing. Modified radical mastoidectomy.
\end{abstract}

\section{Introduction}

Chronic suppurative otitis media (CSOM) is defined as chronic inflammation of middle ear and mastoid cavity that may present with recurrent ear discharges or otorrhoea through a tympanic perforation $^{(1)}$. This disease is more common in developing countries ${ }^{(2)}$ than in developed ones.

CSOM is associated with the structural change in middle ear and permanent abnormality of pars tensa or parse flaccida mostly as a sequelae of long standing middle ear effusion, inadequately treated acute otitis media or eustachian tube dysfunction and negative middle ear pressure.

Under aeration of the middle ear and the alteration of the mechanical properties of the drum such as destruction of the architecture of the collagenous process causing a thinning of tympanic membrane are necessary factors in the development of retraction to cholesteatoma formation ${ }^{[3]}$. The mastoid antrum and air cells when obstructed results in negative pressure in the mastoid leading to oedema and exudates. The interruption of ossicular chain results in hampering middle ear function.

Middle ear surgeries in modern era are more of reconstructive than destructive. The type of surgery opted depends on various factors such as age, otologic findings and status of hearing in both ears.

In modified radical mastoidectomy, Canal Wall Up (CWU) and Canal Wall Down (CWD) mastoidectomy represent the most common 
surgical techniques. The canal wall down procedure the posterior canal wall is taken down till the level of the facial nerve and the floor of the mastoid cavity is continuous with the floor of the external canal. The studies report better functional results in CWU procedure as compared to CWD but recurrence of disease, residual disease and revision surgery is more in CWU. The disadvantages of canal wall down procedure are regular cleaning of cavity, higher occurrence of infection with exposure to water. However these days otolaryngologist obliterate the cavity with different materials to remove these factors. In order to achieve successful hearing improvement it is necessary to assess all the important factors.

\section{Aims and Objectives}

The aim of study was to assess the pre and post operative clinical status and hearing in CSOM cases and study the extent of ossicular chain damage. Also the type of ossicular reconstruction done and different methods of mastoidectomy were evaluated.

\section{Material and Methods}

The present study was done on 64 cases between February 2018 to February 2019. All the CSOM cases who presented to ENT OPD were screened and selected as per our predetermined questionnaire. A detailed history was taken followed by meticulous clinical examination was done to evaluate the patient. Oto-microscopy was done. The history of any previous surgeries was elicited. All the patients with preexisting complications like vertigo, facial nerve paralysis, any intracranial complications, abscesses and preoperative sensorineural deafness were excluded from study. The hearing assessment was done preoperatively and postoperatively by tuning fork test $(256,512,1024 \mathrm{~Hz})$ and pure tone audiometry. Air bone gap was noted in speech frequencies. All the routine haematological and urine examination was done. Radiological assessment in the form of Xray mastoid laws view was done to look for status position of dura and sinuses, any bony erosion or cavity formation. Modified radical mastoidectomy was done with the aim of removal of disease and restoration of hearing. MRM was done by either canal wall up or canal wall down. Ossiculoplasty was done using autologous ossicles or cartilage. Temporalis fascia was used for grafting of tympanic membrane. In postoperative period adequate antibiotics, analgesics were administered \& routine follow up was done. Patients were then asked to follow up after 3 months for condition of graft $\&$ cavity problems. Pure tone audiogram was done at same frequencies in postoperative period and compared with preoperative air bone gap and extent of closure of air bone gap was noted.

\section{Results}

The most common age group was 11-20 years 35 (54.68\%). The other age groups to be affected were 21-30 years with $19(29.68 \%)$ cases followed by 31-40 year $8(12.5 \%)$ and $41-50$ years 2 cases $(3.12 \%)$. The males were predominant in present study i.e. $40(62.5 \%)$ as compared to females $24(37.5 \%)$. The male female ratio was 1.66. The most common complaint was discharge from ear in 60 cases followed by hearing impairment in 58 cases.

The most common perforation was posterosuperior marginal perforation $41(64 \%)$ followed by subtotal perforation $11(17.18 \%)$. The attic perforation $6(9.3 \%)$ was seen in and posterosuperior retraction pocket $3(4.68 \%)$. Polyp was seen in $1(1.56 \%)$. On preaudiometric evaluation air bone gap of $<30 \mathrm{db}$ was seen in 11 $(17.18 \%)$ and air bone gap of $>30 \mathrm{db}$ was seen in $53(82.8 \%)$ patients.

The canal wall down modified radical mastoidectomy was done in $39(60.9 \%)$ while canal wall up MRM was done in 20 (31.25\%) and intact bridge technique was done in $5(7.8 \%)$ patients. The disease involved attic, aditus and antrum and middle ear in $42(65.6 \%)$ cases, disease involving attic, aditus and antrum in 18 $(28.12 \%)$ and disease involving attic only 4 (6.25 $\%$ ) cases. 
The rate of destruction of various ossicles due to CSOM observed while performing surgery are all ossicles malleus, incus and stapes $(\mathrm{O})$ present in 5 (7.8\%), malleus and stapes (A) present in 18 $(28.13 \%)$, malleus absent and stapes present (B) in $34(53.12 \%)$, malleus present and stapes (C) absent in $1(1.5 \%)$, malleus and stapes (D) both absent in $6(9.4 \%)$.

The graft was taken up in $56(87.5 \%)$ cases while residual perforation was seen in $8(12.5 \%)$ cases. The sensorineural hearing loss was present in 9 $(14.06 \%)$ and absent in $55(85.9 \%)$ cases. In patients having less than $30 \mathrm{db}$ preoperative air bone gap less than $20 \mathrm{db}$ air bone gap closure was observed in $1(50 \%)$ case after type II tympanoplasty. In patients having more than 30 $\mathrm{db}$ preoperative air bone gap, less than $20 \mathrm{db}$ air bone gap closure was seen in $2(40 \%)$ in type I Tympanoplasty, $29(58 \%)$ cases with type II tympanoplasty and $5(71.4 \%)$ cases with type III tympanoplasty.

\section{Discussion}

Chronic suppurative otitis media (CSOM) is a chronic inflammation of the middle ear and mastoid cavity.

The most common age group to be affected was $11-20$ year $^{(4,5)}$ with predominance of males ${ }^{(6)}$. The higher incidence of otitis media in first two decades may be due to abundance of lymphoid tissue in children that may obstruct the eustachian tube and increased risk of respiratory infection in children may result in CSOM.

The most common complaint was discharge from ear $60(93.75 \%)$ followed by hearing impairment 58 (90.62 \%). This was in accordance with previous studies. ${ }^{[7,8]}$. Other symptoms were otalgia, headache, vomiting.

$\mathrm{OM}$ is a leading cause of healthcare visits worldwide and its complications are important causes of preventable hearing loss, particularly in the developing world ${ }^{(9)}$

Tubotympanic disease is characterized by a perforation in the parse tensa, are generally called safe from developing complications. Atticoantral disease most commonly involve the pars flaccida and also posterior superior quadrant of pars tensa and is characterized by the formation of a retraction pocket in which keratin and desquamated epithelial debris accumulates to produces cholesteatoma and considered to a dangerous form of the disease because of development of many intracranial and extracranial complications ${ }^{[10,11]}$. The complications are more common in atticoantral variety than tubotympanic type.

The perforation most commonly seen was posterosuperior marginal perforation followed by subtotal perforation. In our study posterosuperior marginal perforation were more because of late presentation of patients during which time retraction pockets gets converted into perforation as compared to previous studies ${ }^{(12,13)}$ where retraction pocket was more common..

The ossicular destruction causes hearing loss in CSOM cases. In CSOM, the ossicular destruction due to granulation was more with increased in duration of ear discharge. The patient may deny hearing loss due to bridging of gap between destructed ossicles by cholesteatoma. The canal wall down procedure was done in $60.9 \%$ cases. In previous studies ${ }^{(14)}$ it was observed that the chances of recurrent disease are more with intact canal wall technique and greater degree of long term safety in which canal wall was removed.

Extensive disease involving attic, aditus, antrum and middle ear was more common in our series as compared to previous studies ${ }^{(15)}$. This could be due to late presentation of patients.

The incus is the most common ossicle affected with malleus being the second most common which is in accordance with previous studies ${ }^{(16,17)}$. Type B was most common followed by type A, type D and type C. This was similar to study done in past (18). In MRM the common cavity is formed after converting the mastoid cavity, epitympanum and external auditory canal into single cavity.

Temporalis fascia was used in all our cases to repair tympanic membrane. The graft uptake was 
seen in 87.5 percent cases, while 12.5 percent had residual perforation.

In patients having less than $30 \mathrm{db}$ preoperative air bone gap less than $20 \mathrm{db}$ air bone gap closure was observed in $1(50 \%)$ case after type II tympanoplasty. In patients having more than 30 $\mathrm{db}$ preoperative air bone gap, less than $20 \mathrm{db}$ air bone gap closure was seen in $2(40 \%)$ in type I Tympanoplasty, $29(58 \%)$ cases with type II tympanoplasty and $5(71.4 \%)$ cases with type III tympanoplasty.

In patients with preoperative air bone gap more than $30 \mathrm{~dB}$, in them more than $20 \mathrm{~dB}$ air bone gap closure was obtained by type I tympanoplasty in $60 \%$ cases, in type II in $21 \%$ cases, type III tympanoplasty in $28.6 \%$ cases.

It was observed that in India a large number of population comes from rural background, have low socioeconomic status and irregular follow up hence one staged procedure is best. The canal wall down procedure with tympanoplasty is beneficial for population of our region.

\section{Conclusion}

It was observed that modified radical mastoidectomy was best with type II tympanoplasty in our setup as ossicular erosion was commonly present.

\section{References}

1. Acuin J. Geneva: World Health Organisation; 2004. Global burden of disease due to chronic suppurative otitis media: Disease, deafness, deaths and DALYs Chronic Suppurative Otitis Media-Burden of Illness and Management Options; pp. 9-23

2. Vikram BK, Khaja N, Udayashankar SG et al. Clinico-epidemiological study of complicated and uncomplicated chronic suppurative otitis media. The Journal of Laryngology \& Otology 2008; 122:442226.

3. Pollock FJ. Pathology of Chronic otitis media. Arch Otolaryngol, 70:421-35, 1959
4. Poorey VK. Study of bacterial flora in CSOM and its clinical significance. Indian Journal of Otolaryngology and Head and neck surgery. 2002 Apr 1; 54(2):91- 5.

5. Vijaya $D$, and Nagarathnamma $T$. Microbiological study of chronic suppurative otitis media. Indian J Otol. 1998 Dec; 4:172-4.

6. Varshney S, and Gupta P. Bacteriological study of chronic suppurative otitis media. Indian Journal of otology. 1999; 5(2):8791.

7. 7 Gulati S P, Sachdeva O P, Kumar A, Chandra R, Sachdeva A (2002Mar); Audiological profile in chronic suppurative otitis media: Indian journal of Otology, vol 8, no 1, 24-28.

8. Behera S K, Mallick K C, Behera S K, clinical assessment of tympanomastoid Surgeries and tympanoplasty with special Reference to hearing status; Odisha Journal of Otolaryngology \& H N S, Vol 8, Issue 1,15-21.

9. Monasta L, Ronfani L, Marchetti F, et al; Burden of disease caused by otitis media: systematic review and global estimates. PLoS One. 20127(4):e36226. Epub 2012 Apr 30

10. Chowdhury MA, Alauddin A.Comparative study between tubotympanic and atticoantral type of chronic suppurative otitis media.Bangladesh Med Res Counc Bull 2002;28(1): 36-44.

11. Mills RP. Scott-Brown's Otolaryngology: 6th ed. Oxford: Butterworth-Heinemann: Management of chronic suppurative otitis media. 1997. Chapter 10

12. Semple Craig W. Mahadevan Murali, Berkowitz Robert G. Annals of otology and laryngology 114(7):539-542,2005.

13. Singh R K, Safaya A. Middle ear hearing restoration using autologous cartilage graft in canal wall down tympanomastoidectomy. Indian journal of otology Vol. 11, 10-14, Dec 2005. 
14. Dodson Edward E, Hashisaki George T et al . Intact canal wall mastoicdectomy with tympanoplasty for choleateatoma in children: Laryngoscope, 108.977-983, July 1998.

15. Joseph, PG, Siba PD. Canal wall down mastoidectomy: experience in 81 cases. Otology \& Neurotology 2001; 22: 451-6.

16. Kurien, M, Job A, Mathew J. Otogenic intracranial abscess: concurrent craniotomy and mastoidectomy: changing trends in a developing country.Arch Otolaryngol 1998; 124: 1353-6.

17. Yavua Uyar, Kayhan Ozturk et al. Anterior atticoantrostomy for cholesteatoma surgery. Annals of otology, rhinology and laryngology. 115 (2): 150155, 2006. 